\title{
On the effects of soaking $\mathrm{CO}_{2}$ laser surface patterned nylon 6,6 samples in simulated body fluid (SBF) in relation to wettability
}

D.G. Waugh and J. Lawrence

Wolfson School of Mechanical and Manufacturing Engineering, Loughborough University, Leicestershire, LE11 3TU, UK

\begin{abstract}
Simulated body fluid (SBF) has been used previously by others to aid in predicting the bioactivity and osseointegration potential of materials. This paper details a study carried out using a $\mathrm{CO}_{2}$ laser to induce a number of surface patterns which inherently modified both the surface chemistry and surface topography giving rise to a difference in apatite response between each sample. These induced patterns gave rise to a reduction in hydrophilicity with contact angles of up to $+10^{\circ}$ being observed. Furthermore, following immersion in SBF for 14 days each sample was weighed revealing an increase in weight of up to $0.029 \mathrm{~g}$ indicating that an apatite layer had begun to form. In addition, energy dispersive X-ray analysis identified the presence of calcium and phosphorous, two elements which support osteoblast cell response. When comparing with an asreceived sample it was found that the laser induced patterned samples gave rise to more layer crystals forming suggesting a more optimized surface for osteoblast cell growth and proliferation.
\end{abstract}

Keywords: $\mathrm{CO}_{2}$ laser, nylon 6,6, wettability, SBF.

\section{Introduction}

It has been demonstrated previously that polymers can be used for biological applications [1,2]. The polymer surface can be optimised for these various applications through surface modification where either the surface topography or surface chemistry is altered. These modifications can be brought about by using numerous methods such as radiation grafting [3], lithography [4], coating technologies [5] and plasma surface modification [6].

Laser surface treatment and patterning [2,7] offers a convenient means of modifying the surface of a material on both the micro- and nano-scale without compromising the bulk properties of the material, which can be seen to be of great importance when applied to fields such as biomimetics. This is on account of previous work which has identified a high dependence of the modifications on cell-material interactions [8].

One can deduce from the literature that a change in the surface chemistry or surface topography will greatly effect the wettability characteristics of a material [9]. As a direct result of this, it would be a great advantage to those throughout the biomedical industry if, by knowing the wettability of a material, one could predict how a material will react in the intended application.

Simulated body Fluid (SBF) has been used previously by others to aid in predicting the bioactivity and osseointegration potential of materials [10]. It should also be noted here that employing SBF experiments in vitro does not fully reproduce the in vivo environment for bone formation however, as stated by Roach et al. [8] these in vitro techniques involving SBF allow for a sufficient rapid screening of materials in the endeavour of development and optimization.

This paper details the effect of soaking nylon 6,6 samples in SBF after $\mathrm{CO} 2$ laser patterning. In addition to this, the characteristic wettability for each sample studied was determined in the endeavour to link wettability to the resulting response of the samples being immersed in SBF.

\section{Experimental Technique}

\subsection{Laser Patterning Procedure, Topography, Wettability and Surface Chemistry}

The details of how the laser patterning procedure and analysis of topography, wettability and surface chemistry can be found in [2]. 5 samples were used for this experimentation; As-received (AR), $50 \mu \mathrm{m}$ trench (T50), $50 \mu \mathrm{m}$ hatch (H50), $100 \mu \mathrm{m}$ trench (T100) and $100 \mu \mathrm{m}$ hatch $(\mathrm{H} 100)$ patterns.

\subsection{In Vitro Simulated Body Fluid (SBF) Experimentation}

Simulated body fluid (SBF) is a liquid which has inorganic ion concentrations equivalent to those of human extracellular fluid (human blood plasma). The SBF was prepared by using a magnetic stirrer hotplate (RCT Basic; 
IKA, GmbH) keeping the solution at a constant temperature of $36.5^{\circ} \mathrm{C} .500 \mathrm{ml}$ of distilled water was put into an autoclaved $1000 \mathrm{ml}$ beaker and stirred until the constant temperature of $36.5^{\circ} \mathrm{C}$ was reached. At this time the chemicals given in Table 1 were added in order until the sodium sulphate (\#9) had been added.

Table 1 - Amounts and order of reagents to prepare $1000 \mathrm{ml}$ SBF

\begin{tabular}{|c|c|c|}
\hline Order & Reagent & Amount \\
\hline 1 & Distilled water & $750 \mathrm{ml}$ \\
\hline 2 & $(\mathrm{NaCl})$ & $7.996 \mathrm{~g}$ \\
\hline 3 & $\left(\mathrm{NaHCO}_{3}\right)$ & $0.350 \mathrm{~g}$ \\
\hline 4 & $(\mathrm{KCl})$ & $0.224 \mathrm{~g}$ \\
\hline 5 & $\left(\mathrm{~K}_{2} \mathrm{HPO}_{4} \cdot 3 \mathrm{H}_{2} \mathrm{O}\right)$ & $0.228 \mathrm{~g}$ \\
\hline 6 & $\left(\mathrm{MgCl}_{2} \cdot 6 \mathrm{H}_{2} 0\right)$ & $0.305 \mathrm{~g}$ \\
\hline 7 & $\left(\sim 0.1 \mathrm{M}\right.$ in $\left.\mathrm{H}_{2} \mathrm{O}\right)(\mathrm{HCl})$ & $40 \mathrm{ml}$ \\
\hline 8 & $\left(\mathrm{CaCl}_{2}\right)$ & $0.278 \mathrm{~g}$ \\
\hline 9 & $\left(\mathrm{Na}_{2} \mathrm{SO}_{4}\right)$ & $0.071 \mathrm{~g}$ \\
\hline 10 & $\left(\mathrm{CH}_{2} \mathrm{OH}\right)_{3} \mathrm{CNH}_{2}$ & $6.057 \mathrm{~g}$ \\
\hline 11 & $\left(\sim 0.1 \mathrm{M}\right.$ in $\left.\mathrm{H}_{2} \mathrm{O}\right)(\mathrm{HCl})$ & Adj. of $\mathrm{pH}$ \\
\hline
\end{tabular}

Once the sodium sulphate (\#9 in Table 1) had been added the Tris(hydroxymethyl) aminomethane (\#10 in Table 1) was supplemented into the solution less than a gram at a time in order to avoid local increase of $\mathrm{pH}$. Finally, in order to adjust the $\mathrm{pH}$ value to 7.4 hydrogen chloride (\#11 in Table 1) was added and the beaker was then filled to $1000 \mathrm{ml}$ using distilled water.

The samples were then placed into sterile $30 \mathrm{ml}$ glass containers, immersed in $30 \mathrm{ml}$ of SBF and placed into an incubator to keep the temperature constant at $37^{\circ} \mathrm{C}$ for 7 days. Prior to being immersed in the SBF the 5 nylon 6,6 samples were weighed using a balance (S-403; Denver Instrument, $\mathrm{GmbH})$. Once the 14 days had elapsed the samples were removed from the SBF, rinsed lightly with distilled water and allowed to air dry in a clean room. Once fully dry the samples were weighed and the difference in weight before and after being immersed in the SBF was determined. Following this the samples were gold coated and analysed using optical microscopy and scanning electron microscopy (SEM). Furthermore, the samples were analysed using EDX in order to identify elements present after the immersion in SBF.

\section{Results and Discussion}

\subsection{Effects of $\mathrm{CO}_{2}$ laser patterning on topography}

From Figure 1 it can be seen that the $\mathrm{CO}_{2}$ laser patterning gave rise to significant modification of the nylon 6,6 surfaces in terms of topography. That is, the laser patterned samples (see Figures 1(b) - (e)) appeared to qualitatively have a considerably larger roughness in comparison to the $3-\mathrm{D}$ profile of the asreceived sample (see Figure 1(a)).

\subsection{Effects of $\mathrm{CO}_{2}$ laser patterning on wettability}

From previous work [2] and available literature [11] it can be seen that surface properties, which are reported to have major influences on the wettability characteristics [12], have the potential to be modified using numerous techniques. Table 2 shows that the roughness had considerably increased using the laser patterning (samples T50, T100 - H100) in comparison to the as-received sample (AR). This contrast can be identified through the $\mathrm{Sa}$ and $\mathrm{Ra}$ roughness parameters insofar as the as-received sample (AR) had an Sa and $\mathrm{Ra}$ of 0.126 and $0.029 \mu \mathrm{m}$, respectively, where the $\mathrm{Sa}$ and $\mathrm{Ra}$ for the laser patterned samples increased by up to 0.51 and $0.156 \mu \mathrm{m}$, respectively. (a)

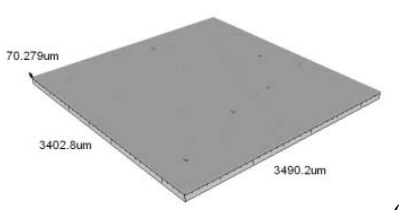

(b)

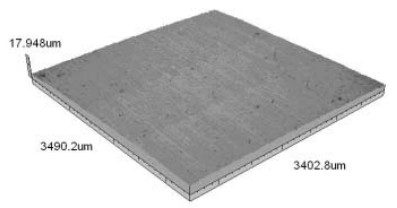

(c)

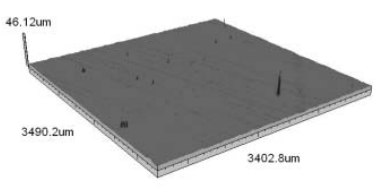

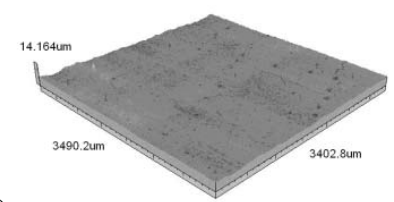

(d) (e)

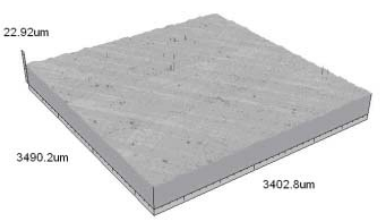

Figure 1 - Continuous axonometric images for each of the nylon 6,6 samples - (a) AR, (b) T50, (c) T100, (d) H50 and (e) H100. 
Table 2 - Results for the surface roughness, contact angle and surface energy parameters for each sample.

\begin{tabular}{|c|c|c|c|c|c|c|c|}
\hline Sample ID & $\begin{array}{c}\mathrm{Sa} \\
(\mu \mathrm{m})\end{array}$ & $\begin{array}{c}\mathrm{Ra} \\
(\mu \mathrm{m})\end{array}$ & $\begin{array}{c}\text { Polar Component, } \\
\gamma^{\mathrm{P}} \\
\left(\mathrm{mJm}^{-2}\right)\end{array}$ & $\begin{array}{c}\text { Dispersive } \\
\text { Component, } \gamma^{\mathrm{D}} \\
\left(\mathrm{mJm}^{-2}\right)\end{array}$ & $\begin{array}{c}\text { Total Surface } \\
\text { Energy, } \gamma^{\mathrm{T}} \\
\left(\mathrm{mJm}^{-2}\right)\end{array}$ & $\begin{array}{c}\text { Surface Oxygen } \\
\text { Content } \\
(\% \text { at. })\end{array}$ & $\begin{array}{c}\text { Contact } \\
\text { Angle } \\
\left({ }^{\circ}\right)\end{array}$ \\
\hline AR & 0.126 & 0.029 & 17.69 & 29.66 & 47.34 & 13.26 & $56.4 \pm 1.2$ \\
\hline T50 & 0.636 & 0.148 & 12.24 & 28.63 & 40.87 & 14.33 & $66.0 \pm 4.0$ \\
\hline T100 & 0.297 & 0.185 & 16.86 & 29.83 & 46.69 & 14.05 & $57.5 \pm 2.4$ \\
\hline H50 & 0.423 & 0.103 & 10.93 & 31.64 & 42.58 & 14.99 & $65.8 \pm 2.9$ \\
\hline H100 & 0.326 & 0.155 & 13.63 & 30.37 & 44.00 & 14.84 & $62.2 \pm 2.3$ \\
\hline
\end{tabular}

The polar component, $\gamma \mathrm{P}$, and total surface energy, $\gamma \mathrm{T}$, two parameters known to potentially affect the wettability [7], decreased significantly for the laser patterned samples (T50, T100-H100). This reduction in surface energies, along with increased surface roughness brought about an apparent increase in contact angle inherently making the nylon 6,6 less hydrophilic. These observations do not necessarily coincide with current theory [7] which states that for a significant increase in surface roughness a hydrophilic material ought to produce a more hydrophilic surface with the contact angle effectively decreasing [13]. It is possible to explain this phenomena by the plausible existence of a mixed state wetting regime, in which both Wenzel and Cassie-Baxter regimes are present over the solid-liquid interface [14].

Table 2 suggests the resulting surface oxygen content may not be the main contributing factor in the outcome of the contact angle. This is owed to, as stated by Hao and Lawrence [7], that a rise in surface oxygen content should give rise to a reduction in the contact; however, as can be seen from Table 3 this is not occurring in this instance.

Finally, the results obtained as seen in Tables 2 and 3 attests an evident and significant rise in contact angle which can be attributed to the reduction in apparent surface energies, $\gamma^{\mathrm{P}}$ and $\gamma^{\mathrm{T}}$, which arise as a direct result of the mixed state wetting regime can be ascribed to the liquid-surface interaction owed to variations in the laserinduced surface topography. As in previous work [2], it can then be extrapolated that both the closely linked apparent surface energies and surface topography appear to be the main driving force in the resulting contact angle.

\subsection{Effects of $\mathrm{CO}_{2}$ laser patterning on SBF response}

From the SEM images (see Figure 2) it was observed that only a very small amount of sediment was present on the as-received sample (see Figure 2(a)) in comparison to the other samples which had undergone $\mathrm{CO}_{2}$ laser patterning (see Figures 2(b) - (e)). This was also confirmed by weighing the samples before and after the immersion in
$\mathrm{SBF}$ as can be seen in Figure 3. That is, the laser patterned samples weighed at least $0.008 \mathrm{~g}$ more than compared to the as-received sample. Following on, it can be extrapolated from this that through $\mathrm{CO}_{2}$ laser patterning of nylon 6,6 the ability to promote the formation of an apatite layer can be sufficiently improved.

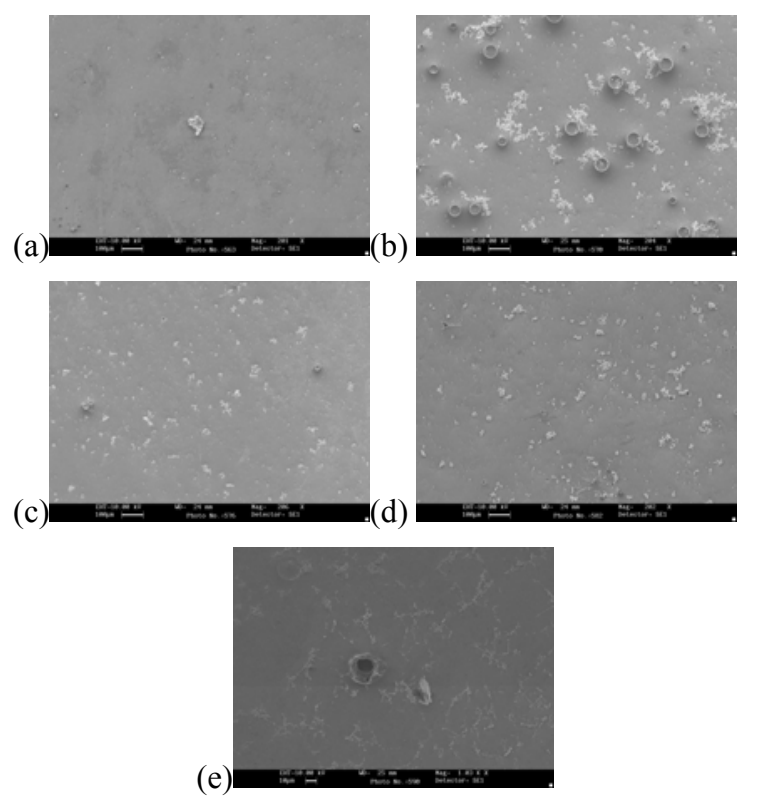

Figure 2 - SEM images of (a) AR, (b) T50, (c) T100, (d) $\mathrm{H} 50$ and (e) H100 after immersion in SBF for 14 days.

From the contact angle results given in Table 2 and the difference in mass shown in Figure 3 it is possible to ascertain that an increase in contact angle has appeared to have a more positive impact on apatite response. What is more, this enhancement in the promotion of apatite layers forming could also be attributed to the significant increase in surface roughness. 
Through EDX analysis it was found that following the formation of the apatite crystals, phosphorous and calcium was present on the surface of the nylon 6,6 samples. This is of importance due to phosphorous and calcium having to be present in order for an apatite to form which would inherently increase the bioactivity of the material. The sediments analysed also incorporated sodium, magnesium and chlorine which had all been present in the SBF and indicates that these elements would also make up some of the apatite layer formed.

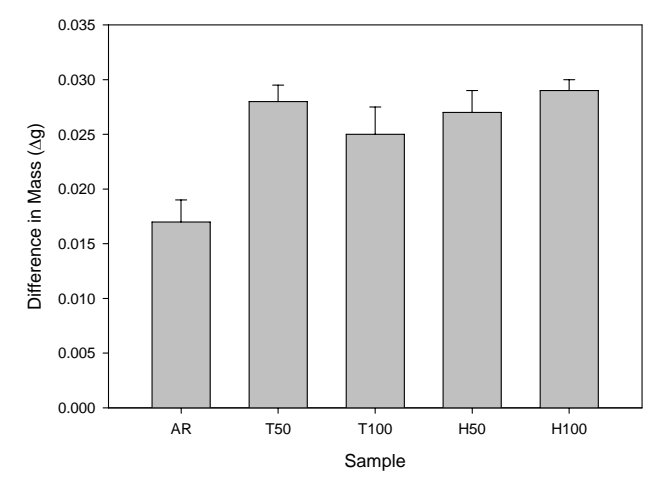

Figure 3 - Difference in mass before and after immersion in SBF for all samples.

\section{Conclusions}

It has been shown through experimentation that a relatively inexpensive $\mathrm{CO}_{2}$ laser marker has the ability to significantly modify the surface properties of nylon 6,6. For instance, the characteristic contact angle increased for the laser patterned samples increased by up to $+10^{\circ}$ in comparison to the as-received sample. This can be explained by the likelyhood of a mixedstate wetting regime which arises through the patterning of the material surface. What is more, the surface modifications have also been seen to have a positive impact on the formation of apatite layers under immersion in SBF, implying that enhanced osteoblast cell response can be achieved using $\mathrm{CO}_{2}$ laser surface treatment when compared to the asreceived sample.

\section{Acknowledgements}

We would like to thank our collaborators Directed Light Inc., East Midlands NHS Innovation Hub, Nobel Biocare and Photomachining Inc. for all of their much appreciated support. The authors, greatly acknowledge the Access to Research Equipment Initiative funded by the EPSRC, (grant number EP/F019823/1) and would like to thank Chemical Engineering, Loughborough University for use of their biological laboratory. This study is also financially supported by the EPSRC, (grant number EP/E046851/1).

\section{References}

[1] Nagano M, Kitsugi T, Nakamura T, Kokubo T, Tanahashi M, (1996) Bone bonding ability of an apatite-coated polymer produced using a biomimetic method: A mechanical and histological study in vivo. Journal of Biomedical Materials Research 31:487-494.

[2] Waugh DG, Lawrence J, Morgan DJ, Thomas CL, (2010) Interaction of $\mathrm{CO}_{2}$ laser-modified nylon with osteoblast cells in relation to wettability. Materials Science in Engineering C 29:25142524 .

[3] Benson RS, (2002) Use of radiation in biomaterials science. Nuclear Instruments and Methods in Physics Research B 191:752757.

[4] David C, Wei J, Lippert T, Wokaun A, (2001) Diffractive grey-tone phase masks for laser ablation lithography. Microelectronic Engineering 57-58:453-460.

[5] Zhao Q, Wang C, Liu Y, Wang S, (2007) Bacterial adhesion on the metal-polymer composite coatings. International Journal of Adhesion \& Adhesives 27:85-91.

[6] Chu PK, (2007) Enhancement of surface properties of biomaterials using plasma-based technologies. Surface and Coatings Technologyrface 201:8076-8082.

[7] Hao L, Lawrence J, (2005) Laser Surface Treatment of BioImplant Materials. New Jersey, USA: John Wiley \& Sons Inc.

[8] Roach P, Eglin D, Rohde K, Perry CC, (2007) Modern biomaterials: a review-bulk properties and implications of surface modifications. Journal of Materials Science: Materials in Medicine 18:1263-1277.

[9] Jung YC, Bhushan B, (2007) Wetting transition of water droplets on superhydrophobic patterned surfaces. Scripta Materialia 57:1057-1060.

[10] Song W, Jun YK, Han Y, Hong SH, (2004) Biomimetic apatite coatings on micro-arc oxidzed titania. Biomaterials 25:33413349 .

[11] Dadbin S, (2002) Surface modification of LDPE film by $\mathrm{CO}_{2}$ pulsed laser irradiation. European Polymer Journal 38:2489-2495.

[12] Zhang J, Kang J, Hu P, Meng Q, (2007) Surface modification of poly(propylene carboante) by oxygen ion implantation. Applied Surface Science 253:5436-5441.

[13] Jung YC, Bhushan B, (2006) Contact angle, adhesion and friction properties of micro- and nanopatterned polymers for superhydrophobicity. Nanotechnology 17:4970-4980.

[14] Lee SM, Kwon TH, (2007) Effects of intrinsic hydrophobicity on wettability of polymer replicas of a superhydrophobic lotus leaf. Journal of Micromechanics and Microengineering 17:687-692. 